\title{
Education Based on Precede-Proceed on Quality of Life in Elderly
}

\author{
Saeed Mazloomymahmoodabad ${ }^{1}$, Gholamreza Masoudy ${ }^{1,2}$, Hosain Fallahzadeh ${ }^{3} \&$ Zahra Jalili $^{4}$ \\ ${ }^{1}$ Department of Health Education and Promotion, Shahid Sadoughi University of Medical Sciences, Yazd, Iran \\ ${ }^{2}$ Health Research Center, Zahedan University of Medical Sciences, Zahedan, Iran \\ ${ }^{3}$ Department of Biostatistics, Shahid Sadoughi University of Medical Sciences, Yazd, IR Iran \\ ${ }^{4}$ School of Medical Sciences, Islamic Azad University (I.A.U), Tehran, Iran \\ Correspondence: Gholamreza Masoudy, Health Research Center, Zahedan University of Medical Sciences, \\ Zahedan, Iran. Tel: 98-915-540-4262.E-mail: masoudy55@yahoo.com
}

Received: May 3, 2014 Accepted: July 14, 2014 Online Published: July 29, 2014

doi:10.5539/gjhs.v6n6p178 URL: http://dx.doi.org/10.5539/gjhs.v6n6p178

\begin{abstract}
Background and Objective: One of the most important challenges in public health is to improve the quality of life in elders. Aging may cause various disorders such as disabilities, high risk conditions and some chronic disease. In this study the effect of educational intervention based on precede-proceed on quality of life in elders was examined.
\end{abstract}

Materials \& Methods: This semi experimental study was carried out on 128 elders over 60 years in Zahedan that were randomly selected by multi-stage sampling method and divided in to control and intervention groups. Data collection tool was a triploid questionnaire that included demographic data, questions of precede-proceed constructs and SF-36 questionnaire. The validity and reliability of questionnaire confirmed by experts and Cranach's Alpha coefficient (76\%). After primary data collecting, educational intervention was performed and after nine months data was collected again and analyzed in spss.16 soft-ware using descriptive and analytical statistics.

Results: The results showed that mean score of quality of life in participants was low and more than $61 \%$ of them had a mean score less than $50 \%$. After intervention the mean score of quality of life only in experimental group significantly increased from 47.72 to 58.90 . Behavior and self-rated health were the strongest predictors for quality of life in this study.

Conclusion: Implementation educational intervention based on precedes-proceed model can improve quality of life in elders. Elderly women and older elderly individuals compared with elderly men and younger elderly should be considering as an important risk factor for reducing HRQOL.

Keywords: education, elderly, precede- proceed, Quality of Life

\section{Introduction}

Aging is an ancient subject and a sensitive period in human life and a normal, biological, universal process and unavoidable phenomenon, (Mudey et al., 2011; Qadri, Ahluwalia, Ganai, Bali, Wani, \& Bashir, 2013; Wu, 2010) From 1965 to 2025, the percentage of elderly persons (aged $\geq 65$ years) is expected to increase by 17 to $82 \%$ in European countries and by about $200 \%$ in some developing countries (Aghamolaei, Tavafian, \& Zare, 2010).

Similar to most other countries, as a result of Improvement in public health and medical advances life expectancy in Iran has increased over the last decades such that it has been measured as 70.3 years in 2005 while it has been 47.2 years in 1960, 52.5 years in 1970, 57.7 years in 1980, 63 years in 1990 and 68.6 years in 2000 (Aghamolaei et al., 2010).

Population aging has many health consequences, including increase in the old-age dependency ratio and disability. Elders have tendency for poorer health status compare younger and population aging cause concerns about potential increases in the number of elderly that suffering of disease and disability (Annear, Cushman, \& Gidlow, 2009).

Finding showed that the psychosocial and social disorders decrease the level of health and quality of life in elderly and has an association with death in elderly (Huong, Hai, Quynh, Hill, \& Walton, 2012; Kumar \& 
Majumdar, 2014; Qiua, Sautterb, Liuc, \& Gud, 2011; Whatley, Dilorio, \& Yeager, 2010). As life expectancy continues rising; one of the greatest challenges of public health is to improve the quality of life in later years of life.

The progressive rise in life expectancy contributes to an increase in the prevalence of chronic illnesses such as Muscular pain, joint pain, restlessness, headache, visual problems, and high blood pressure, cardiovascular disease, digestion and stomach problems, diabetes in the elderly population (Zhou, C. Wang, Yang, Z. Wang, Zheng, \& J. Wang, 2014).These disorders and many other health problems are result of poor health and unsanitary practices

The concept of quality of life contains satisfaction and wellbeing, comprising subjective and multi-dimensional characteristics. Quality of life can be addressed as general quality of life or health-related quality of life (HRQOL) (Lima et al., 2009).

One of the most widely used instruments to assess health-related quality of life is the SF-36 questionnaire (Medical Outcomes Study 36-item Short-Form Health Survey) that is drawn of the Medical Outcomes Study (MOS) questionnaire. SF-36 questionnaire published in English in 1990 (Whatley et al., 2010).

SF-36 translated and validated in several languages and cultures such as Persian and applying in more than 40 countries (Lima et al., 2009; Montazeri, Goshtasebi, Vahdaninia, \& Gandek, 2005).

Each of the sf-36 questionnaire questions refers to one of the following eight different health indicators: physical functioning, role-physical and bodily pain that they refer to the general factor of physical health.

Scales social functioning, role-emotional and mental health measure psychological health and Scales vitality and general health are moderately connected with both factors (Amela et al., 2012; Burholt \& Nash, 2012).

The SF-36 Manual recommended that norm-based scores (NBS) should be used rather than 0-100 scores to simplify interpretation of the data (Burholt \& Nash, 2012).

The elderly in Iran like other developing societies are facing many health and social challenges such as: illiteracy, economic difficulties, problems with daily living, life dissatisfaction, lack of medical insurance, as well as mental and emotional problems (Tajvar, Areab, \& Montazeri, 2008).

In general in health promotion programs, applying models is suggested because models explain how behaviors occur, how health education is applied and how this education affects latter behaviors (Sharifirad, Ghaffari, Zanjani, \& Hassanzadeh., 2012).

Precede-proceed model is a planning model and the best available framework to describe factors influencing health outcomes and provide a comprehensive structure for health needs assessment, program design, implementation and evaluation of health promotion programs, behavior studying, and health promotion (Ekhtiari, Shojaeizadeh, Rahimi Foroushani, Ghofranipour, \& Ahmadi, 2013; Phillips, Rollexy, \& Davidson, 2012).

The PROCEED phases include social, epidemiological, behavioral and environmental, educational and ecological, administrative and policy assessment (Phillips et al., 2012).

Based on precede-proceed model Assumptions and many other finding, predisposing, reinforcing and enabling factors have an effect on behaviors and quality of life (Khaldoun, Aldiabat, \& Navenec, 2013).

Zahedan is one of the southern cities in Iran that located in Sistan and Baloochestan province. Comparison of quality of life mean scores in Zahedan and other cities showed that the mean scores of quality of life of elderly in Zahedan were lower than other cities (Nejati, 2008).

\section{Material and Method}

The sampling method was multi-stage Sampling. In the first stag based on socio economic condition all health centers divided in to 5 sections and then randomly selected a health center of every category. In the next stage from every five health centers, randomly two regions for control and experimental groups were selected.

To obtain the participants based on population ratio in every health center, subjects were selected randomly for both groups (control and intervention). Generally 64 participants for each group selected and surveyed. Data collection tool was a triploid questionnaire included SF-36 questionnaire, demographic items and questions based on precede-proceed model such as knowledge and attitude questions (predisposing factors), reinforcing factors, Behavioral and enabling factors questions.

Regarding the results of a study that showed educational intervention based on elderly family members had a significant impact on quality of life in elderly (Rabiei, Mostafavy, \& Masoudi, 2013), we developed an educational booklet for elder's family that they should study it and support the educational program. Family 
members were asked to help elderly in accomplishing some healthy behaviors such as physical activity, following proper nutrition and medicine adherence.

Besides usual constructs of precede-proceed we added a further construct as environmental construct that included 14 questions about health condition of elderly housing for measuring the physical environment status of participants in this study.

The validity and reliability of questionnaire was approved by content validity method and Cronbach's Alpha coefficient. The validity of questionnaire was confirmed by 10 relevant experts. Cronbach's Alpha coefficient for reliability was 76 percent.

Also we used SF-36 questionnaire for measuring the quality of life and a self-rated health questionnaire to measure the health status of participants. For data collection at first the research objectives were explained and then primary information in both groups were collected and analyzed by SPSS16. Then educational content and curriculum were adjusted based on these. Educational media was a booklet and a video that prepared in two languages [(Persian and baloochy (dialect)].

\section{Results}

A total of 128 individual's age over 60 years participated in this study. The mean age of the participants in the case and control group was 65.80 and 67.80 years, respectively. It was found that 48.4 and 46.6 percent of the participants in the interventional and control group were illiterate. In addition, $82.8 \%$ of the elderly in the case group and $89.1 \%$ of them in control group lived with their spouses and their single children. Also $17.2 \%$ and $21.9 \%$ of participants in the case and control groups had a history of broken bones in their medical history in the past year.

The results showed that no significant difference was seen between two groups before of intervention stage in terms of the level of the education, sex and current source income. Also results from independent $t$ - test before intervention showed that no significant difference was seen between two groups in mean score of the precedeproceed constructs [Knowledge and attitude (predisposing factors), enabling factors, reinforcing factors and behavior] environment conditions, self-rate health and quality of life $(\mathrm{p}>0.05)$ but after the intervention a significant difference was seen $(\mathrm{p}<0.05)$ (Table 1$)$.

Table 1. mean scores of knowledge, attitude, behavior, enabling factors, reinforcing factors, environmentconditions, self-rate health and quality of life in Case and control group in before and after intervention

\begin{tabular}{lllllll}
\hline Variable & \multicolumn{5}{c}{ Before } & \multicolumn{2}{c}{ After } \\
\cline { 2 - 7 } & \multicolumn{1}{c}{ Case } & \multicolumn{1}{c}{ Control } \\
& $\mathrm{M}(\mathrm{SD})$ & $\mathrm{p}$ - value & $\begin{array}{l}\text { case } \\
\mathrm{M}(\mathrm{SD})\end{array}$ & & $\begin{array}{c}\text { Control } \\
\mathrm{M}(\mathrm{SD})\end{array}$ & $\mathrm{p}$ - value \\
\hline knowledge & $20.609(3.16)$ & $21.187(3.67)$ & 0.342 & $24.54(3.54)$ & $19.406(4.67)$ & 0.001 \\
Attitude & $25.6250(3.15)$ & $25.562(2.79)$ & 0.906 & $27.48(2.05)$ & $25.421(2.83)$ & 0.001 \\
Behavior & $14.953(3.76)$ & $14.875(3.78)$ & 0.907 & $18.062(3.7)$ & $15.218(4.142)$ & 0.001 \\
Enabling factors & $19.053(2.39)$ & $19.765(2.38)$ & 0.658 & $21.938(1.94)$ & $19.812(2.31)$ & 0.001 \\
$\begin{array}{l}\text { Reins factor } \\
\text { Environment } \\
\text { conditions }\end{array}$ & $21.953(1.41)$ & $21.546(2.22)$ & 0.220 & $23.078(1.34)$ & $21.187(2.15)$ & 0.001 \\
$\begin{array}{l}\text { Self-rated } \\
\text { health }\end{array}$ & $19.593(1.91)$ & $19.078(1.67)$ & 0.108 & $21.0938(2.15)$ & $19.031(1.69)$ & 0.001 \\
\hline
\end{tabular}

Data are reported as mean (SD)

Also paired T- Test results showed that after the intervention only in case group, the mean scores of the precede -proceed constructs, self-health rated and quality of life significantly increased $(p<0.05)$.

Before intervention, the mean scores of quality of life were 47.72 and 44.73 in the case and control groups, respectively. Before intervention no significant difference was seen between two groups in mean score of SF-36 scales $(p>0.05)$, but after intervention a significant difference between two groups was seen $(p<0.05)$ (Table 
2).

In control group Paired T-Test results showed that no significant difference was seen in mean scores of SF-36 scales group in before and after intervention stages $(\mathrm{p}>0.05)$, but after intervention the mean scores of SF-36 scales in case group were increased significantly $(p<0.05)$.

Pearson's correlation coefficients $(r)$ indicated that quality of life was significantly correlated with knowledge $(r$ $=0.723, \mathrm{p}<.001)$, attitude $(\mathrm{r}=0.311, \mathrm{p}<0.001)$, behavior $(\mathrm{r}=0.665, \mathrm{p}<.001)$, enabling factors $(\mathrm{r}=0.333, \mathrm{p}$ $<.001)$, reinforcing factors $(r=0.440, p<.001)$, environmental condition $(r=0.300, p<.001)$, and self- related health $(\mathrm{r}=0.723, \mathrm{p}<.001)$.

A regression model including behavior $(\beta=0.381$, Standard Error $=0.320, p=0.001)$ and self-health related $(\beta$ $=0.510$, Standard Error $=0.540 \mathrm{p}=0.001)$ was significantly predict the quality of life that explained 0.623 of QOL variances.

Table 2. Mean scores of SF-36 Scales in Experimental and control group in before and after of intervention

\begin{tabular}{lcccccc}
\hline \multirow{2}{*}{ Scale } & \multicolumn{5}{c}{ Before } & \multicolumn{5}{c}{ After } \\
\cline { 2 - 7 } & case & control & P value & $\begin{array}{c}\text { Experimental } \\
\text { M (SD) }\end{array}$ & $\begin{array}{c}\text { control } \\
\text { M (SD) }\end{array}$ & P value \\
\hline $\begin{array}{l}\text { Physical } \\
\text { functioning }\end{array}$ & $38.59(24.93)$ & $39.84(27.00)$ & 0.76 & $50.31(27.03)$ & $38.51(24.71)$ & 0.001 \\
Role-physical & $38.28(33.62)$ & $37.10(34.50)$ & 0.846 & $56.25(34.21)$ & $34.37(34.06)$ & 0.001 \\
Bodily pain & $41.56(25.27)$ & $39.37(27.93)$ & 0.643 & $52.50(25.94)$ & $37.34(28.68)$ & 0.002 \\
$\quad$ General health & $58.59(18.11)$ & $54.29(17.04)$ & 0.169 & $65.39(19.98)$ & $51.17(18.16)$ & 0.001 \\
Vitality & $54.68(22.340$ & $49.21(24.54)$ & 0.190 & $60.93(20.15)$ & $49.68(23.1)$ & 0.004 \\
Role-emotional & $38.02(38.42)$ & $36.45(35.49)$ & 0.812 & $60.93(35.90)$ & $32.29(33.58)$ & 0.001 \\
Social functioning & $46.67(23.80)$ & $43.55(24.8)$ & 0.468 & $54.8(22.004)$ & $43.16(23.66)$ & 0.004 \\
Mental health & $65.37(20.08)$ & $58.06(22.88)$ & 0.057 & $70.00(20.18)$ & $57.37(21.53)$ & 0.001 \\
Quality of life & $47.724(17.82)$ & $44.739(18.92)$ & 0.360 & $58.90(18.57)$ & $42.990(18.75)$ & P<0.00 \\
\hline
\end{tabular}

Data are reported as mean $(\mathrm{SD})$.

\section{Discussion}

The comparison of quality of life of elderly in Zahedan and in some other cities in Iran showed that they had lower mean scores for quality of life and all of the SF-36 health survey scales. This important finding properly suggests that health promotion programs should be considered and implemented (Lima et al., 2009).

Regarding the results of this study, educational intervention based on precedes- proceed increased all of mean scores of precede-proceed, SF-36 health survey scales, and mean score of quality of life in the elderly. Sharifirad et al found similar results after the educational intervention; the case group got higher scores in predisposing (knowledge and attitude), enabling, and reinforcing factors (Sharifirad, Ghaffari, \& Hassanzadeh, 2012).

The present study showed that the mean score of quality of life in elderlies that participated in this study was low and more than $61 \%$ of them had a mean score less than of 50 . Also the present study showed that women compare to men had a lower mean score in quality of life in before and after intervention stage and this results are supported by results of other researches in Iran and other countries which showed that women, old people and low income elderly had poorer health compare men and the younger people. (Aghamolaeil et al., 2011; Franzen, Saveman \& Blomqvist, 2007; Guallar et al., 2005; Francesc et al., 2006).

Regarding this study women and older elderly have more risk factor for reducing HRQOL, and health educational designers, policymakers and health planners should pay more attention to them for designing the more effective interventions to prevent the effects of aging on HRQOL.

The results of independent T-test in before intervention indicated that no significance difference were seen between two groups in mean scores of knowledge, attitude, enabling factors, reinforcing, environment, behavior and self-related health but after intervention there were significant difference among them. 
The results of present study in after educational stage showed that the mean score of quality of life in control group unlike experimental group reduced. It is an important finding because indicated aging and environmental conditional influence the elderly, and there is a necessary for health promotion interventions. This result is supported by some article in Iran or other countries (Thumboo et al., 2003; Chao et al., 2012; Orfila, Ferrer, Lamarca, Tebe, Domingo-Salvany, \& Alonso, 2006).

According to result of linear regression analysis, behavior and self-rated health were the strongest predictors for quality of life, and comparison of this variable in men and women indicated that women have a lower mean score in quality of life.

So we conclude that in health promotion programs designing should pay more attention to women and behavior change programs should be considered and visual media is suggested.

\section{Conclusion}

This study showed that after education intervention based on precede-proceed model the case group got higher scores in knowledge, attitude, behavior, reinforcing and quality of life compare to the control group. So we can conclude that the precede-proceed model provided an applicable framework for apply educational program in elderly.

The analysis of results in present study showed that women compared to men in before and after educational intervention gut lower mean scores in quality of life; therefore it is necessary that in health interventions for promoting healthy behaviors in elders should pay more attention to women.

The results of this study showed that using training videos or booklet that had adequately simple educational pictures were proper strategies to increase of knowledge of elderly.

Also with regard to role of cultural differences, especially different language as a communication barrier, it is necessary that in designing educational program for achieving better results, public health planners should pay more attention to language and cultural conditions of participants.

\section{Acknowledgements}

This study was a part of the PhD dissertation project which supported by health faculty of Shahid Sadoughi University of Medical Sciences, Yazd, Iran. We thank for financial support and appreciate honored members of the department of health education and health promotion of health faculty for their moral and valuable advice also elders of Zahedan and respected theirs families.

\section{Conflicts of Interest}

No conflicts of Interest of each author/contributor.

\section{References}

Aghamolaei, T., Tavafian, S. S., \& Zare, S. (2010). Health Related Quality of Life in Elderly People Living in Bandar Abbas, Iran: A Population-Based Study. Acta Medica Iranica, 48(3), 185-191.

Aghamolaei, T., Tavafian, S. S., \& Zare, S. (2011). Determinants of Health Related Quality of Life on People Living in Bandar Abbas, Iran. Iranian Journal of Public Health, 40, 128-135.

Aldiabat, K. M., \& Lynne Le Navenec, C. (2013). developing smoking cessation program for older Canadian people: an application of Precede-Proceed Developing smoking cessation program for older. American Journal of Nursing Science, 2(3), 33-39. http://dx.doi.org/10.11648/j.ajns.20130203.13

Amela, D., Esad, P., Alen, D., Hasanbegović, I., Mušanović, J., \& Spasojević, N. (2012). The impact of respiratory symptoms presence on quality of life of tobacco smokers. Archives of Pharmacy Practice, 3(4), 274-282. http://dx.doi.org/10.4103/2045-080x.106248.

Annear, M. G., Cushman, G., \& Gidlow, B., (2009). Leisure time physical activity differences among older adults from diverse socioeconomic neighborhoods. Health \& Place, 15, 482-490. http://dx.doi.org/10.1016/j.healthplace.2008.09.005 .

Burholt, V., \& Nash, P. (2011). Short Form 36(SF-36) health survey Questionnaire: normative data for wales. Journal of Public Health, 33(4), 587-603., http://dx.doi.org/10.1093/pubmed/fdr006

Despotovic, N., Milosevic D., Soldatovic. I., Zdravkovic. S., Tomic, S., Mladen, A. (2013). Health-related quality of life in elderly patients hospitalized with chronic heart failure. Clinical Interventions in Aging, 8, 1539-1546. http://dx.doi.org/10.2147/CIA.S53305

Guallar, C. P., Sendino, A. R., Banegas, J. R., Lopez Garcia, E., \& Rodríguez-Artalejo, F. (2005). Differences in 
quality of life between women and men in the older population in Spain. Social Science \& Medicine, 60(6), 1229-1240. http://dx.doi.org/10.1016/j.socscimed.2004.07.003

Hu, J., Wallace, D. C., \& Tesh, A. S. (2010). Health related quality of life among the elderly: a population-based study using SF-36 survey. Journal of Community Health Nursing, 27(2), 70-83. http://dx.doi.org/10.1590/s0102-311x2009001000007

Huong, N. T., Le Thi Hai Ha, N. T., Chi, Q., Hill, P. S., \& Walton, T. (2012). Exploring quality of life among the elderly in Hai Duong province, Vietnam: a rural-urban dialogue. Global health action, 5. http://dx.doi.org/10.3402/gha.v5i0.18874

Kumar, S. G., Majumdar, A., \& Pavithra, G .(2014). Quality of Life (QOL) and its associated factors using WHOQOL Using WHOQOL-BREF among Elderly in Urban Puducherry, India. Journal of Clinical and Diagnostic Research, 8(1), 54-57. http://dx.doi.org/10.7860/jcdr/2014/6996.3917

Lima, M. G., Barros, M. B. D. A., César, C. L. G., Goldbaum, M., Carandina, L., \& Ciconelli, R. M. (2009). Health related quality of life among the elderly: a population-based study using SF-36 survey. Cadernos de saude publica, 25(10), 2159-2167. http://dx.doi.org/10.1590/s0102-311x2009001000007 .

Montazeri, A., Goshtasebi, A., Vahdaninia, M., \& Gandek, B. (2005). The Short Form Health Survey (SF-36): translation and validation study of the Iranian version. Quality of Life Research, 14(3), 875-882 http://dx.doi.org/10.1007/s11136-004-1014-5

Mostafavi, F., Masoudi, R., Hassanzadeh, A., \& Rabiei, L., (2013). The effect of family-based intervention on empowerment of the elders. Journal of education and health promotion, 2(1), 24. http://dx.doi.org/10.4103/2277-9531.112700

Mudey, A., Ambekar, S., Goyal, R. C., Agarekar, \& Wagh, V. V. (2011). Assessment of Quality of Life among Rural and Urban Elderly Population of Wardha District, Maharashtra, India. Ethno Med, 5(2), 89-93.

Nejati, V., Shirinbayan, P., Akbari, A., Kamrani, M., Foroughan, M., \& Taheri, P. (2008). Quality of life in elderly people in kashan, Iran. Middle East Journal of Age and Ageing, 5(2), 21-25. http://www.me-jaa.com.

Orfilaa, F., Ferrera, M., Rosa Lamarcaa, R., Tebeb, C., Antonia Salvanya, D., \& Alonsoa, J. (2006). Gender differences in health-related quality of life among the elderly: The role of objective functional capacity and $\begin{array}{lllll}\text { chronic conditions. Social Science \& } & \text { Medicine., 63(9), 2367-2380. }\end{array}$ http://dx.doi.org/10.1016/j.socscimed.2006.06.017

Phillips, J. L., Rollexy, J. X., \& Davidson, P. M. (2012). Developing Targeted Health Service Interventions Using the PRECEDE-PROCEED Model: Two Australian Case Studies. Nursing Research and Practice, 2012, 1-8. http://dx.doi.org/10.1155/2012/279431

Qadri1, S., Ahluwalia, SK., Ganai1, A., Bali, S., Wani1, F. A., \& Bashir, H. (2013). An epidemiological study on quality of life among rural elderly population of Northern India. International Journal of Medical Science and Public Health, 2(3), 492. http://dx.doi.org/10.5455/ijmsph.2013.2.492-500

Qiua, L, Sautter, J., Liuc, Y., \& Gu, D. (2011). Age and gender differences in linkages of sleep with subsequent mortality and health among very old Chinese. Sleep Med, 12(10), 1008-1017. http://dx.doi.org/10.1016/j.sleep.2011.04.014

Sharifirad, G., Ghaffari, M., Zanjani, S., \& Hassanzadeh, A. (2013) .The effectiveness of educational intervention based on PRECEDE model on the level of stress among the elderly at elderly clubs. Journal of Education and Health Promotion, 1, 11-16. http://dx.doi.org/10.4103/2277-9531.106641

Soleiman Ekhtiari, Y., Shojaeizadeh, D., Rahimi Foroushani, A., Ghofranipour, F., \& Ahmadi, B. (2013) The Effect of an Intervention Based on the PRECEDE- PROCEED Model on Preventive Behaviors of Domestic Violence among Iranian High School Girls. Iranian Red Crescent Medical Journal, 5(1), 21-28. http://dx.doi.org/10.5812/ircmj.3517

Tajvar, M., Arab, M., \& Montazeri, A. (2008). Determinants of health-related quality of life in elderly in Tehran, Iran. BMC Public Health, 8. http://dx.doi.org/10.1186/1471-2458-8-323

Thumboo, J., Fong, K. Y., Machin, D., Chan, S. P., Soh, C. H., Leong K. H., ... Boey, M. L. (2003). Quality of life in an urban Asian population: the impact of ethnicity and socio-economic status. Social Science \& Medicine, 56(8), 1761-1772. http://dx.doi.org/10.1016/s0277-9536(02)00171-5

Whatley, A. D., Dilorio, C. K., \& Yeager, K. (2010). Examining the relationships of depressive symptoms, 
stigma, social support and regimen-specific support on quality of life in adult patients with epilepsy. Health Education Research, 25(4), 575-584. http://dx.doi.org/10.1093/her/cyq001

$\mathrm{Wu}, \mathrm{T}$., \& Functional health status of the elderly in Taiwan. (2010). Healthy Aging \& Clinical Care in the Elderly, 2, 9-17. http://dx.doi.org/10.4137/hacce.s3620

Zahmatkeshan, N., Bagherzade, R., Akaberiyan, .S.H., Yazdankhah, M. R., Mirzaei, K., Yazdanpanah. S, \& Jamand, T. (2012) Assessing Quality of Life and Related Factors in Bushehr's Elderly People. Journal of Fasa University of Medical Sciences, 2(1), P 53-58. (In Persian)

Zhou, Z., Wang, C., Yang. Wang, Z1., Zheng, C., \& Wang, J. (2014). Health-Related Quality of Life and Preferred Health-Seeking Institutions among Rural Elderly Individuals with and without Chronic Conditions: A Population-Based Study in Guangdong Province, China. BioMed Research International, 2014, 1-10. http://dx.doi.org/10.1155/2014/192376

\section{Copyrights}

Copyright for this article is retained by the author(s), with first publication rights granted to the journal.

This is an open-access article distributed under the terms and conditions of the Creative Commons Attribution license (http://creativecommons.org/licenses/by/3.0/). 